\title{
Research on Planning and Optimization of Integrated Energy system for ubiquitous access
}

\author{
Baosheng Chen ${ }^{1}$, Xu han ${ }^{2,}$, Weiqi Zhang ${ }^{1}$, Hankui Tian ${ }^{2}$, Dongni Wei ${ }^{1}$ and Bin Che ${ }^{1}$ \\ ${ }^{1}$ Economic and Technical Research Institute of State Grid Ningxia Electric Power Co., Ltd. China \\ ${ }^{2}$ North China Electric Power University, China
}

\begin{abstract}
With the development of society, people's demand for clean energy is constantly increasing, and it is in this context that the concept of integrated energy systems was born. As the main component of the energy internet, the integrated energy system is now considered to be the main form of energy operation in the future of human society, and the synergistic optimization of different forms of energy can better enhance energy utilization and achieve the effect of $1+1>2$. The planning and design of the comprehensive energy system will involve the data collation and characteristic analysis of energy types, so many factors should be taken into account when planning the specific scheme and operation of the comprehensive energy system's general access, different types of energy forms should be fully considered in the planning of the characteristics of the energy, such as easy control of electrical energy, convenient production, but it is difficult for us to make a decision within a short period of time under normal circumstances.
\end{abstract}

\section{Introduction}

Integrated Energy System (IES) is not a new concept[1], because there are already practices related to the cooperation and optimization of different forms of energy[2], such as Combined Cooling Heating and Power (CCHP) [3], which is to achieve the purpose of cutting peaks and filling valleys through the cooperative optimization of heat and electricity in CCHP[4], improve the utilization efficiency of energy and make the conversion between different forms of energy more flexible[5].

The Ubiquitous Network literally refers to a widespread network for the public and society, which is characterized by omnipresence, omnipresence and omnipotence[6], and is not limited by time, place, personnel and other factors[7]. As one of the important links in the strategic goal of "three types, two networks, world class", the Ubiquitous Electricity Internet of Things (IoT) focuses on each link of the power system and fully applies modern information technology such as mobile internet and artificial intelligence[8]. In addition, advanced communication technology enables the interconnection and human-computer interaction of all aspects of the power system, providing intelligent and convenient services for the planning of the integrated energy system[9].

\section{Key technologies for Integrated Energy Systems}

\author{
2.1. Triple supply of cooling, heating and \\ electricity
}

Combined Cooling, Heating and Power (CCHP) CCHP not only meets the demand for electricity generation, but the heat released will be recycled as a by-product to be used as a heat source for space heating, water heating and space cooling. Compared to a stand-alone heating and power system, a CCHP system is more economically efficient because it not only improves energy efficiency and saves energy, but also reduces fuel and energy costs. The combination of CCHP with renewable energy sources such as biogas, for example, further promotes the energy transition and contributes to the growing greenhouse effect by reducing $\mathrm{CO} 2$ emissions, a potential that cannot be ignored[10].

\subsection{Energy conversion technologies}

The application of this technology focuses on the effective conversion of primary and secondary energy, which makes the value of energy utilization compared to the past has been greatly enhanced, including the common primary energy involving bioenergy, wind and solar energy and other renewable clean energy, secondary energy is mainly electrical energy[11].

\footnotetext{
* Corresponding author: hanxuyy412@163.com
} 


\subsection{Energy storage technology}

The energy storage technology in the comprehensive energy system mainly serves different forms of energy, the main technologies used are generally cold storage technology, heat storage technology, gas storage technology, electricity storage technology, four kinds of energy storage technology applied in the comprehensive energy system, energy storage is efficient and easy to convert and cross-use between different forms of energy[12].

\subsection{Multi-energy cooperative planning and design technology}

By understanding the current resources and economic situation of the target region, we can realize the optimal combination of multiple energy resources and the optimal matching of multiple energy conversion technologies in the region, so that the application of different energy forms can be extended from point to point, from local to systemic, and maximize the benefits.

\section{Integrated Energy System planning and design methodology}

\subsection{Design planning objectives}

The planning and design objectives of comprehensive energy systems should be determined according to local conditions and needs, and should follow the basic principles of safety, reliability and balanced supply and demand, on the basis of meeting users' energy needs, coordinating with the regional policy environment, market conditions and energy structure, and adapting to the overall economic and social development of the region, not only from the economic perspective, but also from the environmental protection and green perspective.

\subsection{Build the theoretical framework of integrated energy system}

The comprehensive energy system is usually composed of supply side, transmission side and demand side. In the face of ubiquitous power IoT, the supply side equipment is divided into independent equipment and coupled equipment; the demand side includes electric load, heat load and cold load. The integrated energy system planning scenario constructed in this paper is shown in the following diagram:

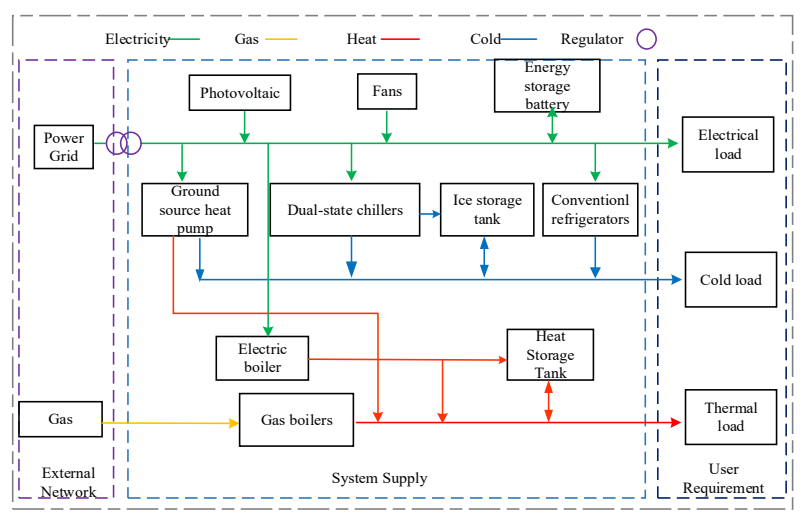

Fig1. Integrated Energy System planning diagram.

\subsection{Optimization model for integrated energy system planning}

\subsubsection{Objective functions}

In this paper, an integrated energy system planning and optimization model is developed based on a fixed investment, with the aim of achieving the lowest overall cost, lowest carbon emissions, and highest overall energy efficiency when the integrated energy system is oriented towards ubiquitous access.

(1) Lowest annualized equivalent cost

The economic operating costs consist mainly of annualized costs such as initial investment in equipment, system operating costs, maintenance costs and depreciation costs, with the following objective functions:

$F_{1}=C_{\text {fin }}=C_{\text {equ }}+C_{\text {ope }}+C_{\text {mai }}+C_{\text {dep }}$

$C_{f i n}$ is the annualized equivalent comprehensive cost; $C_{e q u}$ is the annualized cost of the initial investment in the equipment; $C_{\text {ope }}$ is the operating cost of the system; $C_{\text {mai }}$ is the maintenance cost of the system; $C_{d e p}$ is the depreciation cost of the equipment.

(2) Minimal carbon emissions

$$
F_{2}=\operatorname{minC}_{c i r}=\int_{0}^{t}\left(P_{\text {grid }} \eta_{c o_{2}}+f_{g a s} \omega_{c o_{2}}\right)
$$

min $C_{\text {cir }}$ is the minimum carbon emissions; $P_{\text {grid }}$ and $f_{\text {gas }}$ are the electricity and gas purchases of the integrated energy system, respectively; and $\eta_{\mathrm{Co}_{2}}$ and $\omega_{\mathrm{Co}_{2}}$ are the $\mathrm{CO}_{2}$ emission factors per unit of electricity and gas, respectively.

(3) Highest overall energy efficiency

$$
F_{3}=\max E C=\frac{P_{\text {laod }}}{\text { con }_{\text {ele }}+\text { con }_{\text {gas }} \eta_{\text {gas }}}
$$

$\max E C$ is the maximum combined energy efficiency, $P_{\text {laod }}$ is the system electrical load, con ele and con gas are the electricity and gas consumption, respectively, and $\eta_{\text {gas }}$ is the conversion factor of natural gas to electricity by heat.

\subsection{Constraints}

(1) Energy balance constraint

$$
\left\{\begin{array}{c}
\sum_{i} P_{i}(t)=\sum P_{\text {laod }}(t) \\
\sum_{m} H_{m}(t)=\sum H_{\text {laod }}(t) \\
\sum_{n} L_{n}(t)=\sum L_{\text {laod }}(t)
\end{array}\right.
$$


$P_{\text {laod }}(t), H_{\text {load }}(t)$, and $L_{\text {laod }}(t)$ are the customer's electrical, heating, and cooling loads, respectively; $P_{i}(t)$, $H_{m}(t)$, and $L_{n}(t)$ are the power supply of equipment $\mathrm{i}$, the heating power of equipment $\mathrm{m}$, and the cooling power of equipment $n$, respectively.

(2) Physical constraints on equipment

$$
\left\{\begin{array}{c}
P_{i}^{\min } \leq P_{i}(t) \leq P_{i}^{\max } \\
\operatorname{SOC}^{\text {min }} \leq S O C(t) \leq S O C^{\text {max }}
\end{array}\right.
$$

$P_{i}^{\min }$ and $P_{i}^{\max }$ are the minimum and maximum power of device i, respectively; $P_{i}(t)$ is the real-time output of device $\mathrm{i}$ at moment $\mathrm{t} ; S O C^{\min }$ and $S O C^{\max }$ are the minimum and maximum remaining energy of the energy storage device, respectively; $S O C(t)$ is the remaining energy of the energy storage device at moment i.

\subsubsection{Integrated Energy System planning scenario constraints}

(1) Investment quotas

$$
\left\{\begin{array}{c}
C_{\text {inv }} \leq C_{\text {inv }}^{\max } \\
C_{\text {inv }}=\sum\left(C_{\text {unit_i } i_{\text {init } i}}\right)+C_{L C}
\end{array}\right.
$$

$C_{i n v}$ is the initial investment in the integrated energy system, $C_{i n v}^{\max }$ is the maximum investment that the integrated energy system can afford, $C_{\text {unit } i}$ is the investment cost per unit of capacity of equipment $i$, $Q_{\text {unit_i }}$ is the planned capacity of equipment $\mathrm{i}$, and $C_{L C}$ is the integrated energy.

(2) Energy interaction constraints

$$
\left\{\begin{array}{c}
\left.\boldsymbol{P}_{\boldsymbol{g r i d}}^{\min } \leq \mid \boldsymbol{P}_{\text {grid }}\right\rfloor \leq \boldsymbol{P}_{\text {grid }}^{\max } \\
\boldsymbol{P}_{N G}^{\min } \leq\left\lfloor\boldsymbol{P}_{N G}\right\rfloor \leq \boldsymbol{P}_{N G}^{\max }
\end{array}\right.
$$

$P_{\text {grid }}^{\min }$ and $P_{\text {grid }}^{\max }$ are the minimum and maximum values of the power exchanged between the grid and the integrated energy system, respectively, and $P_{N G}^{\min }$ and $P_{N G}^{\max }$ are the minimum and maximum values of the interaction between the natural gas grid and the integrated energy system, respectively.

\section{Examples of models}

\subsection{Basic data}

In order to verify the validity of the integrated energy system planning and optimization model in this paper, a park in China is selected as a case study for simulation. The annual power load, heat load and cold load are shown in Figure 2, light and wind speed are shown in Figure 3, the technical and economic parameters of the equipment are shown in Table 1, and the performance coefficients of the equipment are shown in Table 2.

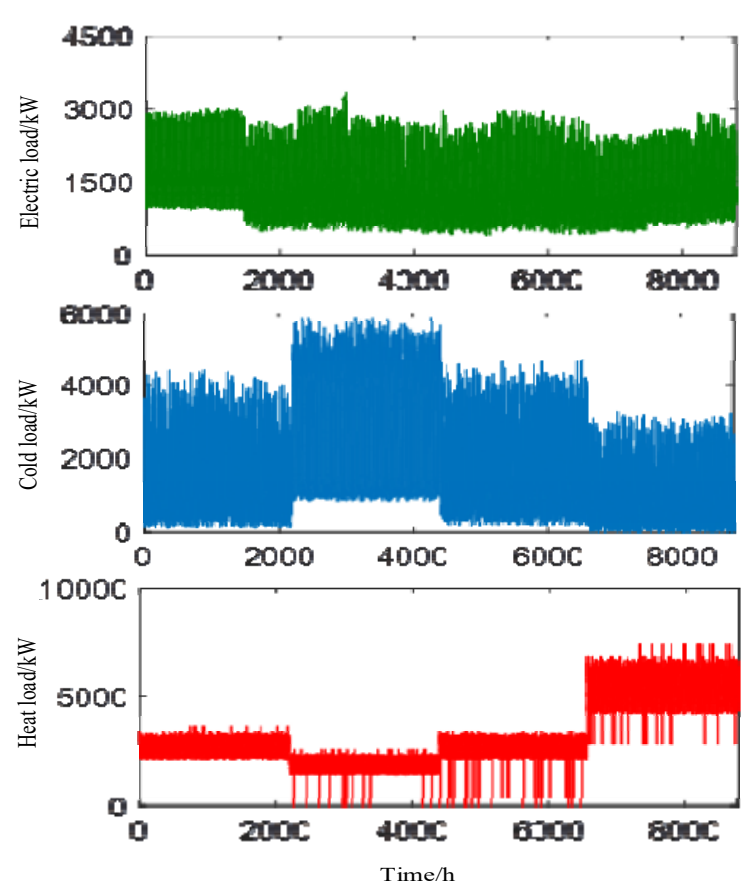

Fig2. Annual thermal and thermal electrical load for 8760 hours.
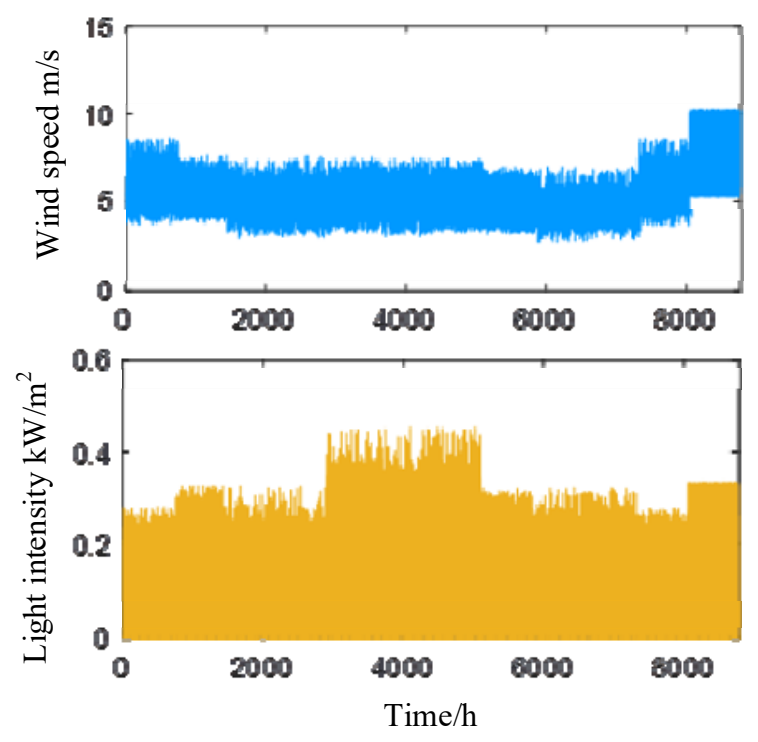

Fig3. Annual wind speed, light intensity for 8760 hours.

Table1. Technical economy of equipment

\begin{tabular}{|c|c|c|}
\hline Equipment & $\begin{array}{c}\text { Amount } \\
\text { invested in } \\
\text { equipment } \\
\text { (Yuan/kW) }\end{array}$ & $\begin{array}{c}\text { Annual } \\
\text { operation and } \\
\text { maintenance } \\
\text { costs } \\
\text { (Yuan/kWh) }\end{array}$ \\
\hline Fans & 7600 & 0.0665 \\
\hline $\begin{array}{c}\text { Photovoltaic } \\
\text { (e.g. cell) }\end{array}$ & 5000 & 0.00125 \\
\hline $\begin{array}{c}\text { Energy storage } \\
\text { battery }\end{array}$ & 2000 & 0.05 \\
\hline $\begin{array}{c}\text { Ground source } \\
\text { heat pump }\end{array}$ & 8000 & 0.05 \\
\hline
\end{tabular}




\begin{tabular}{|c|c|c|}
\hline Electric boiler & 3000 & 0.3 \\
\hline Gas boiler & 3000 & 0.05 \\
\hline $\begin{array}{c}\text { Heat Storage } \\
\text { Tank }\end{array}$ & 200 & 0.7 \\
\hline $\begin{array}{c}\text { Conventional } \\
\text { refrigeration } \\
\text { units }\end{array}$ & 3000 & 0.05 \\
\hline $\begin{array}{c}\text { Dual-state } \\
\text { refrigeration } \\
\text { units }\end{array}$ & 3000 & 0.36 \\
\hline Ice storage tank & 200 & 0.05 \\
\hline
\end{tabular}

Table2. Equipment performance factor.

\begin{tabular}{|c|c|}
\hline Parameters & $\begin{array}{c}\text { Parameter } \\
\text { values }\end{array}$ \\
\hline Electric boiler performance factor & 0.95 \\
\hline $\begin{array}{c}\text { Gas boiler heat generation } \\
\text { efficiency }\end{array}$ & 0.90 \\
\hline $\begin{array}{l}\text { Ground source heat pump } \\
\text { heating/cooling efficiency }\end{array}$ & 3.80 \\
\hline $\begin{array}{l}\text { Thermal storage tank filling and } \\
\text { discharging thermal efficiency }\end{array}$ & 0.90 \\
\hline $\begin{array}{c}\text { Energy storage charge/discharge } \\
\text { efficiency }\end{array}$ & 0.95 \\
\hline Energy storage self-discharge rate & 0.05 \\
\hline $\begin{array}{c}\text { Performance factor for } \\
\text { conventional refrigeration units }\end{array}$ & 4.00 \\
\hline $\begin{array}{l}\text { Refrigeration coefficient for dual- } \\
\text { state refrigeration units }\end{array}$ & 3.00 \\
\hline $\begin{array}{l}\text { Cold storage coefficient of dual- } \\
\text { state refrigeration units }\end{array}$ & 3.00 \\
\hline $\begin{array}{c}\text { Ice storage tank charge/discharge } \\
\text { coefficient }\end{array}$ & 0.98 \\
\hline
\end{tabular}

\subsection{Planning results analysis}

Based on the above data, the Pareto method of solving and sensitivity analysis of the indicators resulted in the following: for the integrated energy efficiency in this case, when the investment quota increases from $\$ 40$ million to $\$ 60$ million, there is an upward trend; when the investment quota increases from $\$ 40$ million to $\$ 65$ million, the annualized equivalent integrated cost of the system shows a downward trend; when the investment quota increases from $\$ 40$ million to $\$ 65$ million, the annualized equivalent integrated cost of the system shows a downward trend; when the investment quota increases from $\$ 40$ million to $\$ 70$ million, the carbon emissions of the system shows a downward trend.

\section{Concluding remarks}

This paper proposes an investment quota-based model for integrated energy system planning based on the need for efficiency of integrated energy system planning in the face of a ubiquitous access to electricity grid scenario, with the following contributions:

(1) A preliminary framework for integrated energy system planning for a quota investment is made to ensure that this integrated energy planning model can ensure the realization of economic, environmental, and social benefits at the time of ubiquitous access.

(2) Optimization of multiple objectives such as annualized equivalent integrated costs, carbon emissions, and integrated energy efficiency and sensitivity analysis of investment quotas are performed to arrive at the most appropriate investment quotas for achieving various benefits.

However, the planning method proposed in this paper is only from the perspective of investors. With the development of integrated energy system and the continuous development and improvement of various pricing mechanisms, the planned integrated energy system in the future will be added to more optimization means in order to get more economical and environmentally friendly planning and allocation scheme.

\section{Acknowledgments}

This paper is supported by "State Grid Ningxia Electric Power Co., Ltd. Management Technology Project (5229JY190013)".

\section{References}

1. Xue Shaohua, Li Ning, Zhou Xingming, Zhang Jingjing, Zhang Zuoyu, Wu Fang, Chen Xiaohui. Optimal operation of integrated energy system considering integrated demand response[J/OL]. Power Demand Side Management,2020(05):7-12 [2020-09-26].

2. Huang Furong, She Jiagui, Yan Aimei, Tian Chuanbo. Planning and Design Method of Integrated Energy System under Energy Internet [A]. Proceedings of the 2019 Workshop on Development and Application of New Technologies for Smart Grid, China Electric Power Research Institute [C]. China Electric Power Research Institute: "Computer Engineering and Applications" Editorial Board, 2019:6.

3. Zhu Chenguang, Tian Yuan, Zhang Yue, Sun Yanling, Guan Shaofeng. An investigation of the planning and design method of integrated energy system under energy internet[J]. Henan Science and Technology, 2020(20):148-150.

4. Cheng Haozhong, Hu Xiao, Wang Li, Liu Yuquan, Yu Qi. Overview of research on regional integrated energy system planning[J]. Power System Automation, 2019,43(07):2-13.

5. Guo Xinhua, Ding Xiaoxiao. Current status and prospect of optimization and operation research of integrated energy system[J]. Power Generation Technology,2020,41(01):2-8.

6. Jiajia Yan, Jin Zhao, Chengyu Zeng, Hong Liu, Jifeng $\mathrm{Li}$, Jide Niu. Analysis of Influencing Factors for Integrated Energy System Planning and Design of Optimal Allocation Scheme in the Park[J/OL]. Modern Electric Power:1-8[2020-09-26]. 
7. Zhang Ning, Wu Xiaoyu, Lu Jing, Tang Fang. Integrated energy system planning methods and tools[J]. Electric Age, 2020(08):24-27.

8. YUAN Zhiyong, ZHAO Yiqi, GUO Joogang, MA Xiyuan, LEI Jinyong, ZHAO Xinyi, SHEN Xinwei, GUO Qinglai. Research Overview on Integrated Energy System Planning for Energy Internet[J]. Southern Power Grid Technology,2019,13(07):1-9.

9. Liu Dunan, Zhang Tingting, Li Hua, Qi Caijuan, Ma Yanxia, Zhang Weiqi, Xu Xiaofeng. A comprehensive energy system planning model for ubiquitous power IoT $[\mathrm{J}]$. Power $\quad$ Generation Technology,2020,41(01):50-55.

10. Deng Xin, Dai Qiongdan. Collaborative Planning of Multi-type and Multi-area Integrated Energy System[J]. Control and Information Technology,2020(03):33-39+44.

11. Wang Yongli, Guo Lu, Zhou Mianhan, Sun Yalai, Liu Lin, Huang Fei-Fei. Research on the planning efficiency of integrated energy system under the condition of quota investment[J/OL]. Power Demand Side Management,2020(05):38-44+57[2020-09-26].

12. Miao Jianjun. Exploration and Practice of Integrated Energy Planning and Optimization Design of Enterprises[J]. Distributed Energy, 2020, 5(04):51-58. 